\title{
12. SURFACE FEATURES ON QUARTZ SAND AND SILT GRAINS: LEG 39 DEEP SEA DRILLING PROJECT
}

\author{
D.H. Krinsley, Queens College, Flushing, N.Y. and Arizona State University, Tempe, Arizona \\ and \\ F.W. McCoy, Lamont-Doherty Geological Observatory, Palisades, New York
}

\section{INTRODUCTION}

The study of surface irregularities on quartz sand grains via Scanning Electron Microscopy (SEM) techniques has developed into a major method for distinguishing sedimentary environments and transport mechanisms. Only a few quartz grains can furnish important information, even though sample numbers may be statistically insignificant. Primarily, it is the breakage and impact with other sand particles of such grains that provides the features caused by mechanical processes seen on grain surfaces; features due to chemical activity can also be discerned through SEM, and a number of criteria for distinguishing these features caused by mechanical and chemical processes and their implications are well established (Krinsley and Doornkamp, 1973).

Deep-sea samples, however, do not contain abundant large sand grains, but do occasionally include fine sand and coarse silt. This study describes SEM work on representative portions of fine sand-coarse silt grains found in cores taken during Leg 39 of the Deep Sea Drilling Project (Figure 1). Generally silts or very fine sands do not seem to contain mechanical surface features because grain to grain collision momentum is not sufficient to initiate breakage. Upon closer inspection however, we have been able to delineate and make use of these smaller grains, an encouraging advancement in SEM methods. Essentially, the silts and fine sands were assumed to be broken fragments of larger sand grains that contained surfaces with preserved mechanical markings, an assumption proven valid and reported here.

\section{METHODS}

Samples were selected from 13 cores at Sites 354,355 , 356,357 , and 358 ; specific information on samples, sample depths, grains studied and their size ranges, and sample ages are given in Table 1. Generally, samples were selected from horizons where sand and coarse silt grains were visible such as from basal turbidite sequences (Sections 355-2-2; 355-6-2; 355-6-4; 356-435), slump deposits (Section 356-39-4), or from particularly sandy and/or silty sediments (all other samples). With the exception of samples from Site 354, every sample represents an interval where smear-slide analyses indicated between $5 \%$ and $45 \%$ quartz. Note, then, that these samples studied all represent displaced material where transport into abyssal depths has occurred rapidly and has probably been quickly buried

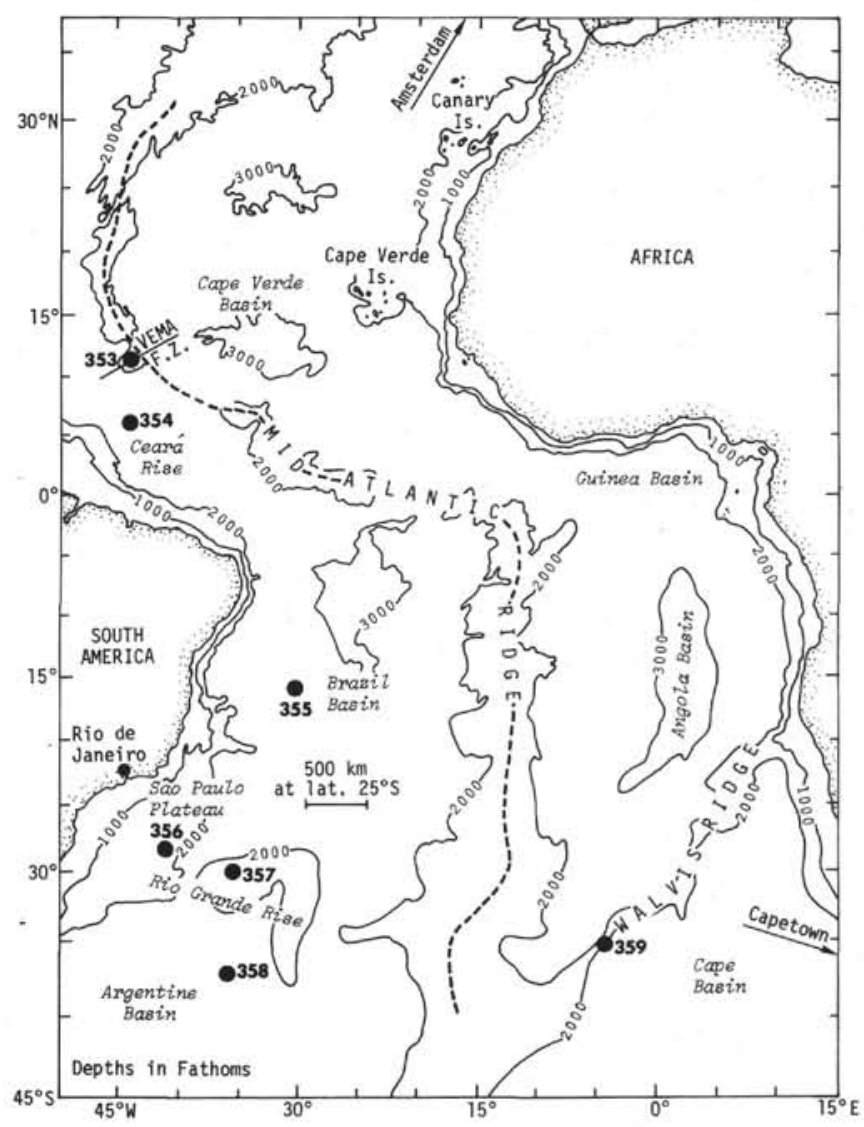

Figure 1. Drilling locations, Leg 39.

by succeeding events. It is, of course, through such a sequence of events that appropriate materials for SEM work on grain surfaces are emplaced.

We examined numerous other samples. The ones reported here are only those that contained apparent and obvious surface textures on quartz, fine sand, and coarse silt grains. Many samples included quartz particles of clay-size and fine-silt size, but these were not appropriate for study.

Each sample was treated with $15 \% \mathrm{HCl}$ to digest calcium carbonate material, dried, weighed, washed over a $44 \mu \mathrm{m}$ sieve; the dry residue was then weighed after being allowed to reach room temperature. After drying, the coarsest quartz components were hand picked under a binocular microscope and mounted on SEM stubs. Selected samples were examined with the polarizing microscope to make certain that quartz was 
TABLE 1

\begin{tabular}{lcccl}
\hline \multicolumn{1}{c}{ Sample } & $\begin{array}{c}\text { No. of Grains } \\
\text { Studied }\end{array}$ & $\begin{array}{c}\text { Grain-size } \\
\text { Range } \\
(\mu \mathrm{m})\end{array}$ & $\begin{array}{c}\text { Sample Depth } \\
\text { Below Sediment } \\
\text { Surface }(\mathrm{m})\end{array}$ & \multicolumn{1}{c}{ Age } \\
\hline $354-15, \mathrm{CC}$ & 4 & $125-150$ & 819.25 & Upper Paleocene \\
$354-17, \mathrm{CC}$ & 9 & $115-145$ & 857.25 & Maestrichtian \\
$355-2-2$ & 13 & $185-320$ & 111.80 & Upper Miocene \\
$355-6-2$ & 6 & $80-170$ & 264.10 & Middle Eocene \\
$355-6-4$ & 6 & $220-600$ & 266.60 & Middle Eocene \\
$356-16-2$ & 2 & $105-150$ & 287.02 & Lower Eocene \\
$356-38-3$ & 2 & $110-130$ & 649.59 & Santonian \\
$356-39-4$ & 20 & $140-750$ & 680.05 & Coniacian \\
$356-43-5$ & 12 & $240-600$ & 728.97 & Albian \\
$357-21$, CC & 8 & $125-370$ & 288.75 & Middle Eocene \\
$357-46-3$ & 1 & 225 & 746.60 & Santonian \\
$358-9-3$ & 3 & $75-135$ & 592.29 & Middle Oligocene \\
$358-15-1$ & 4 & $125-150$ & 798.70 & Maestrichtian \\
\hline
\end{tabular}

not confused with sanadine or volcanic glass (Margolis, 1975). All samples were then coated with a layer of Pt$\mathrm{Pd}$ and examined and photographed with the scanning electron microscope (SEM). The number of grains available varied considerably from one sample to another. Generally, all that were present were used if the sample contained less than 20 grains; for those samples containing more than 20 grains, only 20 were examined and photographed. We have found that this number of grains will provide as much information as could be obtained from three times the number. Features used to define modern sedimentary environments and transport mechanisms are listed in various publications (Krinsley and Margolis, 1969; Krinsley and Doornkamp, 1973; Whalley and Krinsley, 1974; Krinsley, Friend and Klimentidis, 1976).

\section{RESULTS}

\section{Site 354}

Two samples which included very fine sand-sized quartz were examined, with 13 grains exhibiting determinable surface textures (Table 1). Grain size varied between 110 and $150 \mu \mathrm{m}$. Most commonly, these grains contained freshly broken surfaces (Figures 2, 3). In Section 354-15-6, from an Eocene marly nannofossilchalk on the Ceará Rise, one grain had a preserved rounded surface while two other grains contained preserved etch pits; no definitive textures were present. The other Section, 354-17-6, was taken from a Maestrichtian pale red calcareous marl. Here preserved surfaces indicated a moderate to high turbulence beach and shelf regime with "V"-shaped impact markings; we also observed one rounded surface and some etched features suggesting dune action. The Maestrichtian sample thus indicates that it was subjected to abrasion in dunes and on beaches.

\section{Site 355}

Three samples from the Brazil Basin site contained grain surfaces with detectable surface markings, two with sand grains, one with silt grains.

Section 355-2-2 (see Table 1) was taken from an Upper Miocene mud in the Brazil Basin (Figure 1)

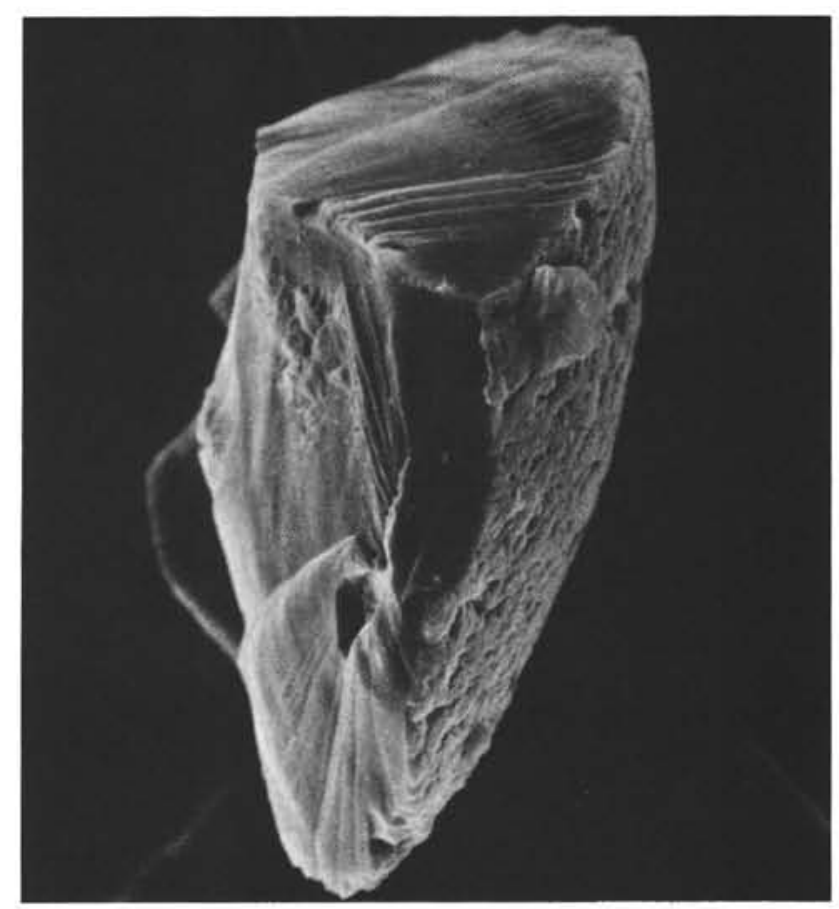

Figure 2. Fine quartz sand grain (130 $\mathrm{\mu m}$ maximum diameter) from Site 354 showing aeolian action (plate formation) on the right side with conchoidal breakage patterns on all other portions of the grain. This specimen was broken, probably by a single blow following dune action. Note rounding on aeolian area. $10 \mu \mathrm{m}=7.2 \mathrm{~mm}$. Maestrichtian.

within a sequence of numerous thin turbidite sequences. It had unfortunately been disturbed by drilling, and the actual position of the material within a turbidite cannot be determined. Smear-slide analysis indicates it contains up to $10 \%$ quartz. Thirteen sand grains were studied (Table 1), all of fine sand size (185 to $320 \mu \mathrm{m}$ ). Most grains were probably eroded from granites, granite gneisses (Figure 4), or sandstones (Coch and Krinsley, in preparation; Donahue and Krinsley, in preparation), and contained no sedimentary mechanical features. However, three of the 


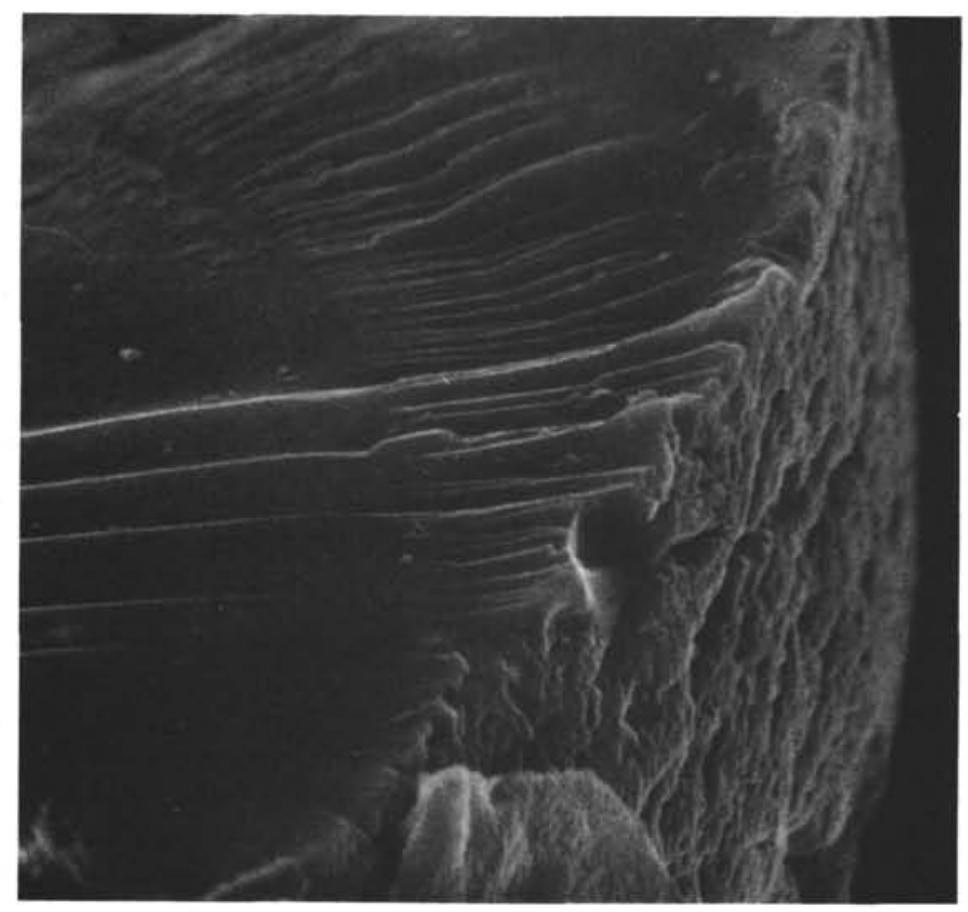

Figure 3. Close up of grain in Figure 2. Note sharp contact between aeolian and conchoidal surfaces. Also note that the conchoidal surface is completely fresh, without solution or precipitation. $10 \mu \mathrm{m}=30 \mathrm{~mm}$. Maestrichtian.

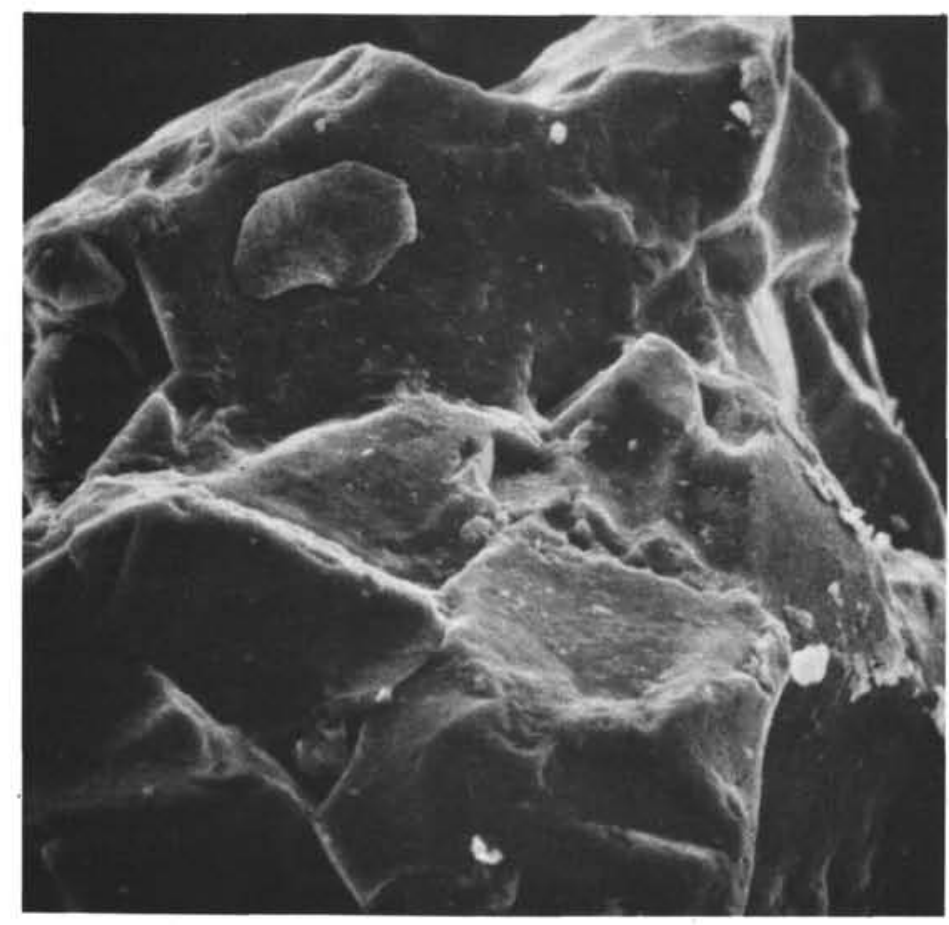

Figure 4. Portion of a fine quartz sand grain showing microblock texture suggestive of a granite or granite gneiss origin (Site 355). Note small particle embedded in upper right microblock; this is probably an inclusion. Inclusions are generally observed only on freshly weathered granites and granite gneisses which have not been transported a great distance. $10 \mu \mathrm{m}=6 \mathrm{~mm}$. Upper Miocene. 
grains included numerous characteristics indicative of littoral zone erosion-mechanical "V"'shaped depressions, conchoidal fractures-and a moderate to high turbulence beach and shelf environment is indicated (Figures 5, 6). Precipitation is also evident; this occurred before littoral erosion as the mechanical features were formed on the solution surface. One possible aeolian grain with a pitted but rounded and frosted surface texture was also observed; chemical precipitation is also suggested. This combination of surface texture features would suggest a hot desert area behind a high-energy beach with possibly a wide shelf offshore.

Silt-sized grains with a few preserved "V"-shaped grooves, etch marks, some precipitation and recrystallization, and a number of rounded surfaces were seen in Section 355-6-2; limited beach and hot dune action seems possible. This material was taken from a sandy silty pelagic clay where a $20 \%$ quartz content was suggested from smear slides. It forms the basal unit of a thin turbidite unit, within a thick packet of Eocene turbidites cored here in the Brazil Basin.

As the basal portion of another Eocene turbidite, the Brazil Basin (Figure 1) Section 355-6-4 contains up to $45 \%$ quartz from smear-slide analyses. It is a quartz sand with a high zeolite content (see also McCoy et al., this volume). Six sand grains studied (Table 1) were of fine to medium sand-size (220 to $600 \mu \mathrm{m})$ and included

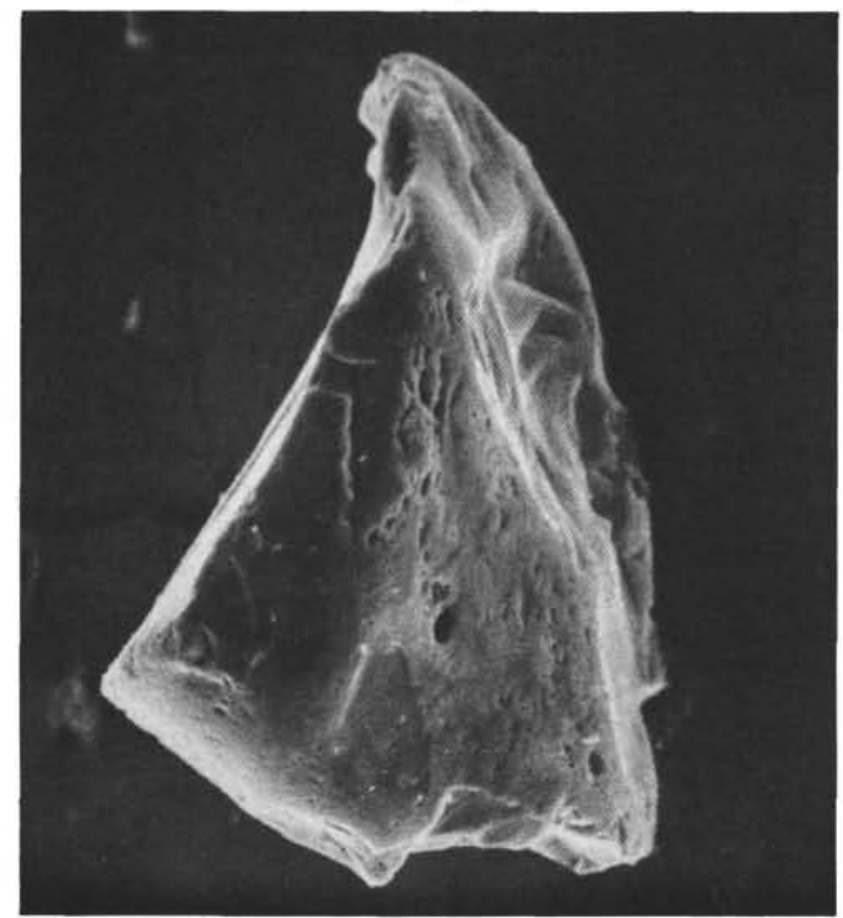

Figure 5. Broken fine quartz sand grain ( $300 \mu$ m diameter) from Site 355 with eroded surface facing toward the front. Close ups indicate that this front surface was formed on a medium to high energy beach. The grain was probably broken after beach action. $10 \mu \mathrm{m}=$ $2.8 \mathrm{~mm}$. Upper Miocene.
"V"-shaped patterns on rounded corners indicative of subaqueous abrasion, while a number also contained etch patterns due to chemical dissolution. Grain surfaces were very clean with no evidence of chemical precipitation. Crystals of zeolite are scattered on grain surfaces, some even resting within the mechanically formed " $V$ "-shaped depressions; no evidence of chemical reaction between the zeolites and quartz grains exists (see Plate 1, in McCoy et al., this volume).

This assortment of grain surface features suggests that the grains remained on a South American shoreline for a fairly long period of time during which the "V"-shaped patterns were developed by grain to grain impact. Margolis (1968) in studying the distribution of mechanically "V"-shaped patterns and etch pits on quartz sand-grains surfaces from beaches with varying wave energy conditions along the Gulf and Atlantic coasts of the United States, showed that where such mechanical and chemical features both occurred on individual grain surfaces, the range of mean wave height lay between 25 and $50 \mathrm{~cm}$. Data in our paper suggest that mean wave height on the Eocene beach from where this sample was abraded was probably also within this range. Residence time in this Eocene littoral zone may have been long as the etch pits suggest extended periods of time during which the grains were protected from wave action perhaps in relatively quiet pools or lagoons, where chemical etching could take place. Following this, the grains were then transported across a shelf, and into the Brazil Basin. Since Eocene time, remarkably little diagenesis has occurred on sand surfaces after deposition and burial.

\section{Site 356}

Here, four samples contained particles with interpretable surface markings on quartz sand and silt surfaces. Only two fine sand grains in Section 356-16-2 were sufficiently large to be studied; one from a silicified nannofossil chalk in the late Eocene of the São Paulo Plateau included evidence of wave action. A Santonian sample, 356-38-3, from a marly calcareous chalk included, on one fine sand fragment evidence of dune action. The quartz content in both samples was between $5 \%$ and $10 \%$ based upon optical determination in smear slides.

Sand-sized quartz grains in Section 356-39-4 may be considered representative of those within the sandy silty claystone forming the matrix of the Coniacian clay pebble conglomerates on the São Paulo Plateau. A quartz content of between $20 \%-30 \%$ is suggested from smear-slide analysis. Twenty grains were studied (Table $1)$, ranging in diameter from very fine to coarse sand (140 to $750 \mu \mathrm{m}$ ). Most of the grains probably weathered from granites or granite gneisses, although some may have originated in sandstone; such a derivation would be indicated by the presence of microblocks on the former (Coch and Krinsley, in preparation) and quartz crystal terminations on the latter (Donahue and Krinsley, in preparation). One grain may have been resident in the littoral zone. Few larger grains 


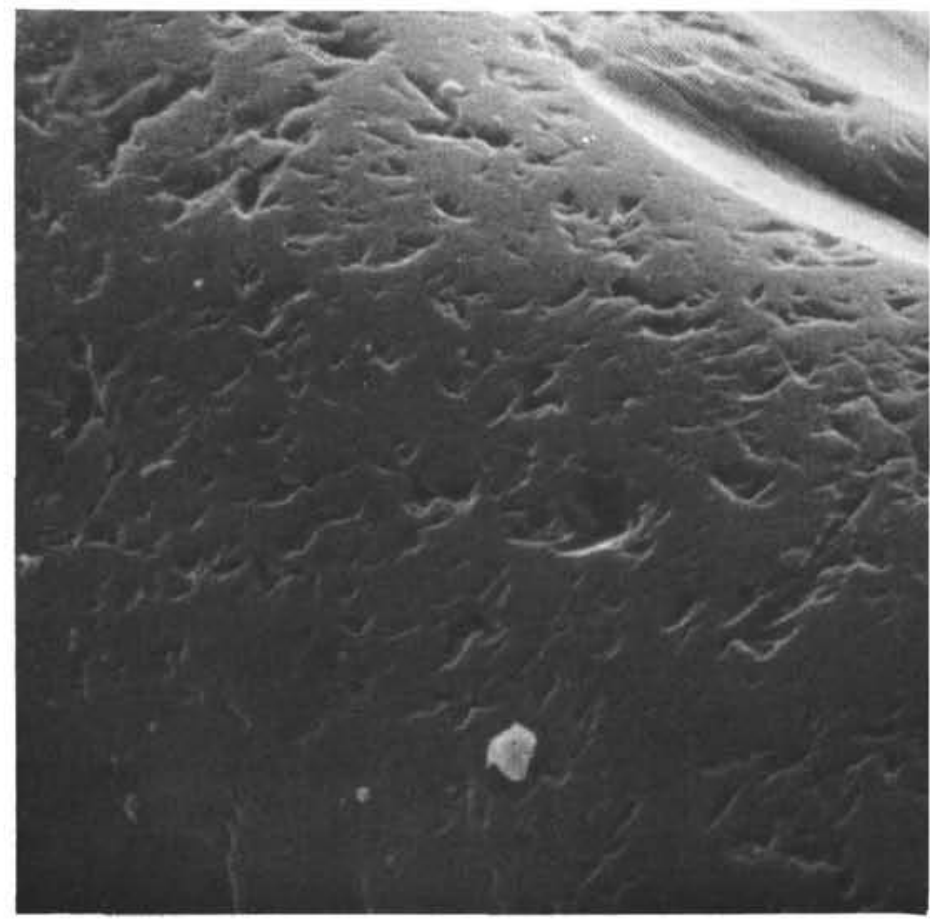

Figure 6. Close up of grain in Figure 5. Note mechnical Vshaped patterns and straight or slightly curved scratches characteristic of subaqueous beach action. $10 \mu m=5 \mathrm{~cm}$. Upper Miocene.

contained evidence of solution and precipitation. Because littoral markings are generally absent, either wave-energy was limited, or the offshore shelf was narrow and the grains passed rapidly into deeper water. Quartz sands in Section 356-43-5 were taken from an Albian graded turbidite sequence where a $10 \%$ quartz content is suggested by smear-slide analysis of nearby sediment.

Of the 12 grains examined, ranging from fine to medium sand ( 240 to $600 \mu \mathrm{m}$ ) in size (Table 1), three suggested an extensive, hot aeolian environment as indicated by rounded shapes, impact pits, and precipitation within small cavities; these grains represent a hot, rather extensive desert environment, perhaps on the order of the Sahara of today and probably larger than modern North American deserts. A high energy, hot, moist environment such as exists in Nigeria at present as indicated by cracking, crazing and solution on quartz surfaces (Figures 7,8 ) is also suggested, (see, for example, Doornkamp and Krinsley, 1971). Other grains contained additional evidence of etching and precipitation and are somewhat irregular in shape; the form and surface textures are indicative of weathered igneous or granitic rocks. Small quartz crystal growths on two grains suggest a derivation through the subaerial disintegration of sandstones. There is no evidence of subaqueous littoral action, again indicating a short residence time in shallower water or in an area where wave energy was limited. Particles may have been carried quickly across a narrow shelf into deeper water.

\section{Site 357}

On the Rio Grande Rise, two samples were found where sands and silts contained surface markings adequate for study. Sands were separated from a middle Eocene nannofossil chalk where optical data does not indicate quartz in smear slides, but elsewhere in the portion of Site 357 there are thin graded horizons with glauconite, quartz and feldspar (see Site 357, this volume). All eight grains studied (Section 357-21-66) (Table 1) were of fine sand size (125 to $370 \mu \mathrm{m})$ and most were flat in shape; this probably due to a breakage mechanism along cleavage planes characteristic at these sizes (Krinsley and Smalley, 1973). Precipitation and solution features were ubiquitous (Figure 9) and no mechanical features were observed, with the exception of one rounded grain with upturned plates characteristic of aeolian action (Margolis and Krinsley, 1971). As solution and precipitation are very common on grains from hot deserts and one of eight grains contained aeolian textures, it is possible that the source of this material represents a desert of the Sahara type (Krinsley et al., 1976).

One silt grain was found within a silty marly limestone from the Rio Grande Rise (Sample 357-46-3) that contained dune features. Again an aeolian environment is probable.

\section{Site 358}

Silts from an Oligocene siliceous mudstone (Sample 358-9-3) and Maestrichtian red-brown marly chalk 


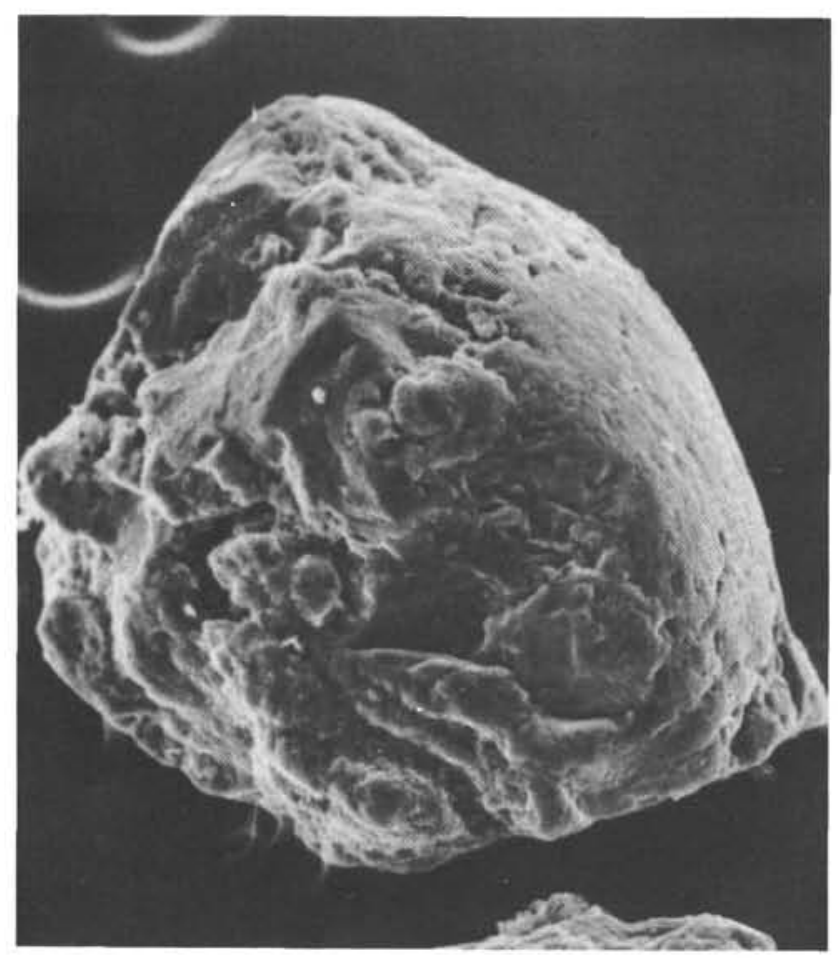

Figure 7. Rounded fine sand grain from Site 356 with an irregular left side ( $270 \mu m$, maximum diameter). The rounded area may be partly aeolian. $10 \mu \mathrm{m}=2.8 \mathrm{~mm}$. Albian.
(Sample 358-15-1) (Table 1) contained some "V"shaped impact pits, dune features, and some preserved rounded grain surfaces but not in sufficient quantities to be definitive. Other surfaces appeared to be freshly broken and were typical of mostly all grains observed in this study. Optical data on the Maestrichtian sample indicates a $15 \%$ quartz content.

\section{DISCUSSION AND CONCLUSIONS}

Approximately $80 \%$ of the very fine sand-silt grains (in the $75 \mu \mathrm{m}$ to $150 \mu \mathrm{m}$ size range) were composite, that is, they contained a surface or surfaces with mechanical features, either aeolian or subaqueous, and an additional surface that had been a portion of a larger quartz sand grain. The broken surface typically had large conchoidal breakage patterns which, even in older samples such as from the Early Cretaceous, contained no evidence of diagenesis even at magnifications of $10,000 \times$. The original size of the grain from which the broken piece of fine sand or silt originated, or spalled, could frequently be determined from the curvature of the older, curved surface.

Spalling must have followed aeolian and subaqueous action. The preserved, original surfaces were generally complete; in particular the aeolian surfaces were wellrounded and did not differ from those seen in modern dune sands. Surprisingly few solution and precipitation features were present on the dune portions of the sands, in contrast to modern sands from hot deserts such as the Sahara, suggesting that perhaps ancient desert

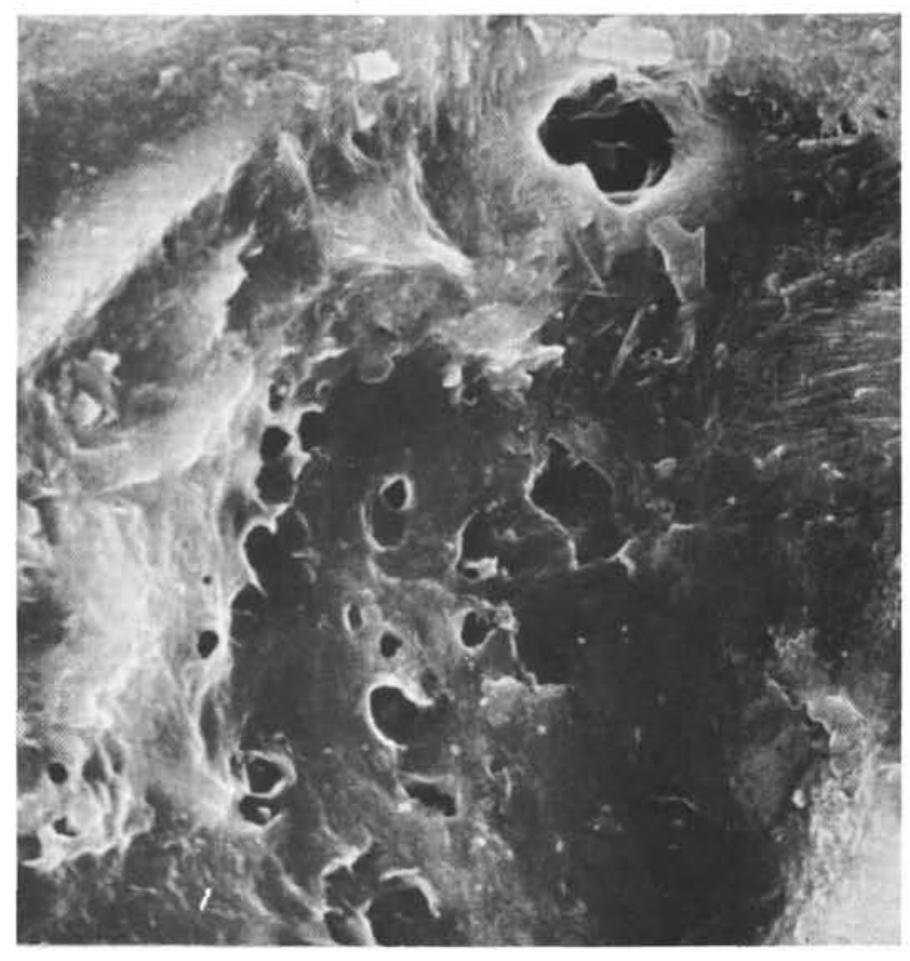

Figure 8. Close up of a portion of the grain in Figure 7. Note irregular depressions and slight surface peeling; this type of feature suggests solution in a hot, wet environment. $10 \mu \mathrm{m}=$ $30 \mathrm{~mm}$. Albian. 


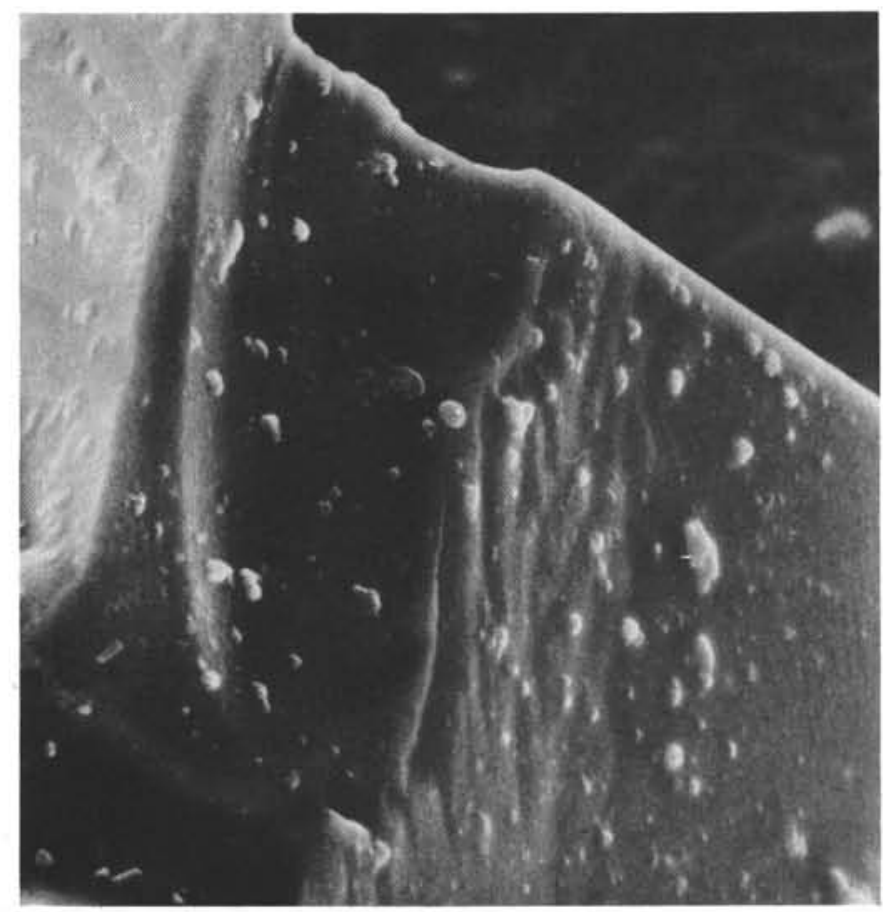

Figure 9. Portion of a fine sand grain from Site 357 showing precipitation. Apparently the small surface blobs precipitated on the large microblock surfaces and then were covered with precipitated silica. $10 \mu \mathrm{m}=10 \mathrm{~mm}$. Middle Eocene.

climates differed in some aspects from modern ones. However, the existence of a large ancient desert or deserts during the Cretaceous must be postulated because the grains from which the small fragments came were well rounded and contained well-developed upturned plates.

Final breakage apparently took place after aeolian and subaqueous action and was caused by sharp and sudden impacts. Sand grains which managed to survive aeolian and subaqueous action long enough to acquire a mechanical surface patina must have been strong and not at all similar to weak quartz, which is commonly riddled with cracks caused by the weathering of granites (Krinsley and Smalley, 1973). Thus the sand grains were probably abraded in desert and/or subaqueous environments, then transported across the shelf and into deeper water. The breakage event producing fine sand and silt particles occurred during turbidity current movement, but it is difficult to see how "strong" grains of the type described above could have been broken even in traction transport.

The large percentage of broken grains and the fact that indications of breakage were found at numerous stratigraphic levels suggest that this process was common and continuous from at least the Lower Cretaceous to the upper Eocene. Large conchoidal surfaces are free of any type of feature indicative of chemical action, and diagenetic processes thus could not have been significant over a time period of more than $100,000,000$ years. Possibly quartz diagenesis only occurs if grains are in contact with carbonate or are uplifted above the marine environment thereby permitting ground water circulation.
The mechanical processes of breakage, therefore, must be important in size reduction of grains through time in the world's oceans. In addition, and more importantly, silt and fine-sand sized grains can be used for paleoenvironmental determinations even though the original quartz grains were either too large to be transported to the deep ocean or did not form an important part of the sediment.

Many grains, including silts, point to desert conditions on land; transport to the deep sea for some samples may also have taken place by aeolian action. The Albian sample from the São Paulo Plateau (Section 356-43-5) indicates extensive deserts, on the order of the modern Sahara Desert, possibly backed by highlands where warm climates promoted extensive chemical weathering somewhat similar to present-day environments in Nigeria. This desert may have been the Botucatu-Sambaiba desert described by Bigarella (1972); generally arid conditions here during the Mesozoic have also been noted by Butler (1970). Here wind directions determined from cross-bedding dip directions in outcrops suggest that offshore winds would have existed in the southern portion of the paleodesert blowing east and northeast towards the São Paulo Plateau area. Such arid conditions, of course, have been indicated in the Aptian during the deposition of evaporites (Leyden, et al., 1976; Burke, 1971; and many others).

Just north of this area, high rainfall occurred due to mixing of air masses (Bigarella, 1972). It may have been in this area where chemical weathering of granites, granite gneisses and sandstones took place-the source rock lithologies indicated from our SEM work. Such 
rocks would be characteristic of shield areas now present on the Brazilian Shield.

By Coniacian-Santonian time, aeolian indicators were still present on grains both on the São Paulo Plateau (Section 356-38-3) and on the Rio Grande Rise (Section 357-46-3). Sand grains point to continued chemical erosion of a highland with exposed granites and gneisses. In the Argentine Basin, aeolian transport probably occurred during the Maestrichtian (Section 358-15-1).

Evidence for aeolian conditions is not as strong throughout the Tertiary. Rather, surface textures exhibit features that denote abrasion in the littoral zone. Interestingly, such textural imprints are not as characteristic in the Cretaceous sediments. Thus, through much of the Tertiary, erosion of detritus to the nearshore zone (some of which may have been dune sands and silts as indicated, for example, by sections 355-2-2, 355-6-2, 355-6-4, 356-16-2) provided an input of terrigenous material to the continental shelves where it was subsequently moved offshore into deeper water. All samples, with the exception of Section 358-9-3, are Eocene and Miocene in age. This corresponds to two major episodes of terrigenous sediment influx into the western South Atlantic Ocean (see McCoy and Zimmerman, this volume) that could be related to uplift and erosion in Southern Brazil and Uruguay during the middle Tertiary (Butler, 1970).

The Oligocene in the South Atlantic is obscured by numerous unconformities and hiatuses in the deep-sea record (see McCoy and Zimmerman, this volume), but the one Oligocene sample from the Argentine Basin (Section 358-9-3) suggests some degree of aeolian activity in Argentina with silt particles transported into the basin by either winds or currents. A strong thermohaline circulation had developed here by the end of the Oligocene (McCoy and Zimmerman, this volume) and currents would seem the more likely mechanism; the silts themselves may represent pre-Oligocene material and environmental conditions. This sample did not contain any grains indicative of glacial activity in contrast to modern sediments (Krinsley et al., 1973).

All indicators from both the Cretaceous and Tertiary suggest narrow continental shelves and limited nearshore under a low to medium wave-energy regime. Transport of sand and silt grains out of this environment appears to have been rapid, first across the shelves and then often into the deep-sea through turbidity currents.

The use of coarse silt and fine sand-sized particles represents a new and important application of SEM observations on quartz grain surface.

\section{ACKNOWLEDGMENTS}

We thank J. Thiede for supplying us some samples from washed residues as part of his coarse fraction analysis. We also wish to thank Daniel Lawson for SEM photographic help. D.H. Krinsley acknowledges partial support of this research by the Research Foundation of the City University of New York, Grant Number 11093.

This manuscript has been critically reviewed by $\mathrm{H}$. Zimmerman, K. Perch-Nielsen, and P. Supko.

\section{REFERENCES}

Bigarella, J.J., 1972. Eolian environments-their characteristics, recognition, and importance. In Rigby, J.K. and Hamblin, W.K. (Eds.), Recognition of Ancient Sedimentary Environments, Soc. Econ. Paleont. Mineral. Spec. Publ. No. 16, p. 12-62.

Burke, K., Dessauvagie, T.F.J. and Whiteman, A.J., 1971. Opening of the Gulf of Guinea and geological history of the Benue depression and Niger Delta; Nature Phys. Sci., v. 233 , p. $51-55$.

Butler, L.W., 1970. Shallow structure of the continental margin, Southern Brazil and Uruguay; Geol. Soc. Am. Bull., v. 81, p. 1079-1096.

Coch, C. and Krinsley, D., in preparation. Surface textures of quartz sand grains from Coolidge Creek, Black Hills, South Dakota. 11 th Ann. N.E. \& S.E. Sec. Meeting, Geol. Soc. Am., Arlington, Va. p. 152-153, Abstr.

Doornkamp, J. and Krinsley, D., 1971. Electron microscopy applied to quartz grains from a tropical environment. Sedimentology, v. 17, p. 89-101.

Krinsley, D.H., Biscaye, P. and Turekian, K., 1973. Argentine basin sediments as indicated by quartz surface textures. J. Sediment. Petrol., v. 43, p. 251-257.

Krinsley, D. and Doornkamp, J., 1973. Atlas of quartz sand surface textures, Cambridge University Press, Cambridge, England. $91 \mathrm{p}$.

Krinsley, D. and Smalley, I., 1973. Shape and nature of small sedimentary quartz particles. Science, v. 180 , p. 1277 1279.

Krinsley, D., Friend, P. and Klimentidis, R., 1976. Eolian transport textures on the surfaces of sand grains of early Triassic age. Geol. Soc. Am. Bull., v. 87, p. 130-132.

Leyden, R., Asmus, H., Zembruski, S. and Bryan, G., 1976. South Atlantic diapiric structures; Bull. Am. Assoc. Petrol. Geol., v. 60, p. 196-212.

Margolis, S., 1968. Electron microscopy of chemical solution and mechanical abrasion features on quartz sand grains. Sed. Geol., v. 2, p. 243-256.

Margolis, S., 1975. Paleoglacial history of Antarctica inferred from analysis of Leg 29 sediments by scanning electron microscopy. In Kennett, J.P., Houtz, R.E., et al., Initial Reports of the Deep Sea Drilling Project, Volume 29: Washington (U.S. Government Printing Office), p. 10391048.

Margolis, S. and Krinsley, D., 1971. Submicroscopic frosting on eolian and subaqueous quartz sand grains. Geol. Soc. Am. Bull., v. 82, p. 3395-3406.

Whalley, W.B. and Krinsley, D.H., 1974. A scanning electron microscope study of surface textures of quartz grains from glacial environments. Sed., v. 21 , v. 87-105. 